\title{
MILITARIZAÇÃO VOLUMÉTRICA NO RIO DE JANEIRO: ENTRE O TRÁFICO DE DROGAS E O POLICIAMENTO
}

\author{
Márcio José Mendonça* \\ Universidade Federal do Espírito Santo
}

Resumo: Este estudo discorre sobre o processo de militarização volumétrica no Rio de Janeiro, que se dá por empregar dispositivos de vigilância fundados no controle de volumes em vez de áreas ou redes. Tais perspectivas se concretizam em virtude da territorialização dos traficantes de drogas ilícitas nas favelas e nos bairros segregados e da intervenção por parte do Estado via a instalação das Unidades da Polícia Pacificadora (UPPs). Argumenta-se que a militarização em curso no Rio de Janeiro tem transfigurado o espaço urbano e produzido um espaço de batalha complexo, acentuando os conflitos intestinais que ocorrem nas favelas e áreas segregadas da cidade.

Palavras-chave: Volume Político. Militarização. Espaço de Batalha.

\section{VOLUMETRIC MILITARIZATION IN RIO DE JANEIRO: BETWEEN DRUG TRAFFICKING AND POLICING}

Abstract: This study deals with the process of volumetric militarization in Rio de Janeiro, which is due to the use of surveillance devices based on the control of volumes rather than areas or networks. Such perspectives are materialized by the territorialisation of illicit drug traffickers in segregated slums and neighborhoods and by state intervention through the installation of the Pacifying Police Units (UPPs in Portuguese). It is argued that the militarization under way in Rio de Janeiro has transfigured urban space and produced a complex battlespace, accentuating the intestinal conflicts that occur in favelas and segregated areas of the city.

Keywords: Political Volume. Militarization. Battlespace

\section{MILITARIZACIÓN VOLUMÉTRICA EN RÍO DE JANEIRO: ENTRE EL TRÁFICO DE DROGAS Y LA POLICÍA}

Resumen: Este estudio discurre sobre el proceso de militarización volumétrica en Río de Janeiro, que se da por emplear dispositivos de vigilancia fundados en el control de volúmenes en lugar de áreas o redes. Tales perspectivas se concretan en virtud de la territorialización de los traficantes de drogas ilegales en las favelas y barrios segregados y de la intervención por parte del Estado vía la instalación de las Unidades de la Policía Pacificadora (UPPs). Se argumenta que la militarización en curso en Río de Janeiro ha transfigurado el espacio urbano y producido un espacio de batalla complejo, al acentuar los conflictos intestinales que ocurren en las favelas y áreas segregadas de la ciudad.

Palabras clave: Volumen Político. Militarización. Espacio de Batalla. 
Introdução à concepção de geopolítica vertical

0 presente estudo reflete sobre o processo de militarização da cidade do Rio de Janeiro, que se dá pela aplicação de concepções do urbanismo militar. Tais concepções se traduzem no espaço pela produção de políticas volumétricas de controle territorial. Estas têm se dado, inicialmente, como destaca Graham (2011), a partir da imersão de um momento paradigmático do fenômeno da militarização da cidade, que coloca a vida urbana em permanente estado de conflito, manifesto, no caso carioca, na territorialização do tráfico de drogas nos morros e bairros segregados da cidade e na adoção de políticas públicas de segurança que metaforizam o discurso da guerra contra o tráfico de drogas, contra o crime de forma mais geral e contra toda e qualquer forma de insurgência, traduzida como uma ameaça à ordem pública.

O urbanismo militar, ideia central deste trabalho, evoca que atividades militares têm interferido na vida urbana ao ministrar táticas de controle urbano e ao criar espaços militarizados. Estes, uma vez engendrados por perspectivas de controle tridimensional e vertical do terreno urbano, transfiguram a experiência de vida na cidade, submetida, agora, aos dispositivos de controle que ampliam a sensação de medo e militarização do cotidiano, ao mesmo tempo em que têm conduzido a cidade a uma era de "guerra permanente". No que tange à realidade brasileira, a militarização urbana se insere no quadro mais amplo das desigualdades sociais, de cunho histórico, em que há mediações culturais e socioeconômicas na repressão seletiva de criminosos socialmente excluídos e na atuação de agentes do Estado baseada na criação de estereótipos de fundo racista, sendo essas mediações a todo momento reformuladas à custa dos mais vulneráveis, orientando-nos por padrões colhidos no discurso da mídia e do Estado, considerando os mais pobres como os inimigos.

Em outras palavras, trata-se de uma sociedade que se militariza não para a guerra voltada contra o estrangeiro, o inimigo externo, mas para o conflito contra o intitulado inimigo interno ${ }^{1}$ da sociedade brasileira. 0 tráfico de drogas, ou simplesmente o crime de forma geral, rotulado como o inimigo da Nação após o processo de abertura política e redemocratização, abrange, nesse viés, populações excluídas do mercado de trabalho e desprovidas de acesso pleno às condições de cidadania, tratadas enfaticamente como inimigas potenciais da Nação, tidas como a parcela da sociedade que mais tem

'Para mais detalhes sobre a criminalização e a violência contra a população pobre desencadeada, mais enfaticamente, após o período de redemocratização nos anos 1980, consultar Soares (2000), Batista (2003), Misse (2011) e, finalmente, Alves e Evanson (2013) propensão a se rebela contra o sistema, ou a cometer atentados contra a vida das pessoas e crimes contra o patrimônio. Por isso, são reprimidas de forma violenta pelos agentes do Estado, diferentemente do que ocorre com outros grupos sociais.

Extremamente vulneráveis à lógica de exploração que os condiciona como trabalhadores de baixa remuneração, muitos à margem da sociedade de consumo e plena de direitos, a população pobre é apresentada como uma ameaça para as pessoas ditas de "bem" (ou que têm "bens") e, até mesmo, à ordem pública. $O$ efeito mais perverso de tal concepção alcança a política pública e o setor privado, que, amparados por estruturas discursivas que constroem uma justificativa inculcada no conjunto da sociedade como "verdade", legitimam políticas urbanas e militares de contenção da população mais pobre, ou até mesmo de expulsão desse segmento, tido como indesejável, redesenhando, assim, o mapa urbano da cidade. Nessa guerra de vizinhança, a cidade cadentemente se transforma no palco de conflitos de uma verdadeira imaginação geográfica, que redefine áreas abandonadas pelo mercado como zonas de exclusão, habitadas por "arruaceiros" e "criminosos"; enquanto a cidade legal propriamente dita é habitada pelas classes dominantes e demais grupos inseridos na lógica do consumo, portanto, bem servidos de equipamentos sociais. Diferentemente das populações que moram em favelas e bairros populares, esses grupos exercem seus direitos e são reconhecidos plenamente como cidadãos.

A mudança paradigmática que reformula 0 pensamento militarista de guerra contra os pobres origina-se de concepções do urbanismo militar, que retroalimenta o conceito de guerra em espaços comuns e em espaços privados das cidades, bem como em sua infraestrutura. Tal doutrina orienta uma condição perpétua de guerra contra as drogas, contra o terrorismo, contra o crime e, em sentido mais amplo, contra toda situação de insegurança (ver GRAHAM, 2011). Para Graham (2011), a violência política e militar está de volta às cidades e está se baseando numa doutrina de dominação oriunda do período colonial: está ressurgindo no período pós-colonial de guerras contemporâneas travadas no hemisfério sul, sendo estas agora adotadas nas cidades do Norte como modelos de segurança².

${ }^{2}$ Graham utiliza os termos hemisfério norte e hemisfério sul para distinguir cidades de países capitalistas "desenvolvidos" de "subdesenvolvidos". O mais correto, a nosso ver, seria diferenciar e estabelecer uma correlação com o nível de desenvolvimento capitalista e o quadro de urbanização que dê conta da mediação entre os que dominam e os que são dominados, ao mesmo tempo em que faça menção às tipologias de urbanização. Desse modo, referindo-se ainda mais especificamente ao "desenvolvimento urbano", julgamos ser necessária a compreensão de um desenvolvimento urbano autêntico que abarque uma mudança social positiva em seu sentido, não restrita ao emprego de noções simplistas de desenvolvimento econômico ou social submetidas às concepções de crescimento econômico e de modernização tecnológica, que não são equânimes com relação à transformação das relações sociais e do espaço para os mais pobres. 
No Rio de Janeiro, a militarização da cidade leva-nos a disputas pelo controle do terreno urbano entre o tráfico de drogas, grupos milicianos e o Estado. Este último, ao combater o comércio ilícito de drogas, encontra na cidade o seu palco de ação manifesta na repressão não só de grupos armados, mas de civis, tão logo, da vida urbana. Nessa perspectiva, considera-se que o terreno urbano tem sido qualificado como espaço de batalha de um claro processo de urbanização da guerra, que entremeia parâmetros de exclusão urbana não só definidos por condicionantes econômicos e culturais, mas também expressos pelo militarismo. Por essas premissas, a guerra vivida em seu cotidiano tem encontrado na Cidade Maravilhosa seu lugar de retorno.

Do enfoque privilegiado, não se trata de enfatizar que a cidade é um lugar violento a priori, mas de compreender o processo de militarização da cidade engendrada por um urbanismo que se utiliza de concepções de guerra, colocadas em prática como "políticas de segurança" (efetuadas no Brasil tanto por grupos independentes quanto pelo Estado), que visam, por suas estratégias, estabelecer o controle sobre o território. Nesse sentido, nosso objetivo é compreender a militarização do urbano como uma arquitetura de controle sobre o espaço urbano (construído) da favela, quando age sobre esse lugar, o estereótipo do "caótico" e do "bandido", via de regra para legitimar operações militares e justificar a ausência de políticas sociais mais incisivas por parte do Estado. Assim, um ambiente urbano extremamente complexo, que inclui as favelas e apresenta inúmeras ruas e vielas, túneis, áreas verticalizadas etc., tenderia a ser cada vez mais concebido como campo de batalha em perspectiva tridimensional a partir da lógica da militarização volumétrica.

Tal perspectiva enfatiza, entre outras coisas, uma noção geopolítica da cidade que não considera o espaço urbano uma superfície a partir da noção clássica da cartografia, em que temos a distribuição de objetos num plano horizontal. 0 espaço, mais do que isso, passaria a ser concebido como um volume político ${ }^{3}$ constituído por horizontalidades e verticalidade que se intercruzam, criando um holograma territorial que pode ser subdivido em estratos ou camadas espaciais que expressam um ambiente tridimensional (WEIZMAN, 2002, 2004, 2012).

Neste cenário, as condições de combate "face a face" entre tropas regulares numa concepção de guerra tradicional, disputada em espaços amplos e abertos, são cada vez mais incomuns: os conflitos recentes têm se

${ }^{3}$ Volume político é o termo usado por Weizman (2002, 2004, 2012) que faz menção às estruturas e aos objetos que não apenas dividem o espaço, mas também funcionam como sistemas ópticos de controle a partir de uma matriz militar disposta em volume, em vez de, no sentido mais convencional, superfície ou área. dado cada vez mais em espaço urbano denso ${ }^{4}$.

Nessa perspectiva, a pesquisa se insere no campo dos recentes estudos em Geopolítica Vertical. Estes mostram a transformação da cidade como um todo num espaço de batalha complexo que envolve uma noção volumétrica costumeiramente tomada, em grande medida, como lócus de práticas de guerra urbana destinadas, no fundo, além de vencer o inimigo, a destruir o seu habitat, negando-lhe a cidade como substrato de reprodução ou mesmo de esconderijo. Assim, o que estamos vendo nos conflitos recentes, em diferentes locais, é um processo de destruição da urbanidade da cidade, com o objetivo de negá-la ao inimigo, ou seja, criar uma situação de "genocídio urbano", o qual diferentes autores têm definido como urbicídio $^{5}$, isto é: a negação deliberada ou a simples destruição da urbanidade que propicia a vida na cidade. No caso do Rio de Janeiro, objeto de análise neste estudo, embora não seja uma guerra "declarada" e de alta intensidade, a política de militarização volumétrica tem transfigurado o espaço urbano, produzindo uma espécie de urbicídio volumétrico.

A reflexão aqui, então desenvolvida, demonstra que a violência política praticada pelo Estado ou por grupos independentes, como o tráfico de drogas, age sobre o meio urbano configurando volumes políticos de controle, mas também, espaços urbicidas onde se verifica a "destruição" do espaço urbano como plataforma de socialização. $O$ urbicídio ocorreria em sentido volumétrico quando é perceptível que a destruição da condição urbana de habitar a cidade reflete um comportamento espacial volumétrico que opera por várias cavidades, camadas ou estratos espaciais. Em tal ação, o Estado, ao agir preferencialmente com violência em bairros habitados pelas classes populares, acaba por considerar nessa situação não o indivíduo, mas o substrato urbano onde reside esse grupo, no caso a favela, o ambiente de repressão e o próprio inimigo do Estado. Por outro lado, o tráfico também contribui por engendrar espaços militarizados que incorrem na supressão e negação do espaço urbano ao produzir áreas deflagradas. Pontos de venda e redes de distribuição da droga com frequência são alvos de disputas entre grupos rivais. $\mathrm{Na}$ espiral de violência, não é incomum que moradores de um bairro dominado por certa facção sejam tidos como inimigos por outra facção, pelo simples motivo de residirem no território controlado por um grupo rival.

Nesse sentido, a temática da cidade concebida como

${ }^{4}$ No que tange ao debate sobre conflito em terreno urbano, travados em meio à infraestrutura física da cidade, orientamo-nos a partir dos estudos de Weizman (2002, 2004, 2012), Graham (2011) e Graham \& Hewitt (2012).

${ }^{5}$ Para um enfoque original e conceitual sobre o urbicídio, ver o estudo de Coward (2009). Para uma leitura dos aspectos volumétricos do urbicídio, ver Sharp (2016). 
um espaço de batalha será posta em análise através das estratégias de militarização efetuadas pelo tráfico de drogas e pelo Estado, que se revelam por meio de dispositivos de segurança que agem sobre o espaço urbano da favela, desenvolvendo formas urbicidas de gestão do espaço urbano que estão reconfigurando espacialmente e redefinindo conceitualmente as favelas e periferias urbanas do Rio de Janeiro. Essa "espacialização" do conflito em conteúdo volumétrico em vez da noção de superfície ou área reflete justamente a guinada da dimensão espacial dos estudos em urbanismo militar, que emprega concepções de volume na análise espacial. Tal metodologia de análise foca, portanto, no estudo do Rio de Janeiro, na distribuição de objetos ópticos de vigilância ao longo do gradiente topográfico dos morros, sob o qual o tráfico e a polícia exercem uma política de controle que se estende, em geral, a toda a população favelada. Focalizados dessa forma por agentes estatais e pelo próprio tráfico, favelas e bairros segregados são concebidos como locais de conflito "permanente".

Neste estudo, para demonstrar o processo de militarização da cidade, além de leitura de bibliografia específica sobre o tema e consulta na rede de computadores, recorremos à leitura de jornais e a duas visitas de campo de cunho observatório no Rio de Janeiro, no morro da Rocinha (no dia 11 de agosto de 2016) e no morro de Santa Marta (no dia 4 de abril de 2017), com intuito de verificar empiricamente como se constatam e se integram lógicas de militarização imersas no cotidiano e na vida dos moradores na favela, que se dão, simultaneamente, pelo tráfico e pelo policiamento ostensivo ${ }^{6}$.

Procuramos demonstrar a compreensão do território urbanizado munindo-nos do conceito de volume político, que orientará a análise do espaço urbano em áreas de conflito. Volume político expresso como uma noção de percepção tridimensional do território, como área de segurança em seu sentido político-estratégico, que subdivide o espaço em estratos espaciais, ou volumes, que vão do espaço subterrâneo ao espaço aéreo, será o mote de análise na pesquisa. Tal estudo lança luz sobre a noção volumétrica de controle do território, muito empregada nos estudos em Geopolítica Urbana, que integram o quadro mais amplo do que se chama Geopolítica Vertical. Aspira-se, com esse procedimento, corresponder ao objetivo geral da pesquisa, a saber: apresentar um panorama de como a cidade do Rio de

${ }^{6}$ Sobre as referências bibliográficas que serviram de fonte de informação histórica e empírica para compreensão das dinâmicas territoriais do tráfico de drogas e da polícia, baseamo-nos nos estudos de Soares (2000), Barcellos (2003), Batista (2003), Misse (2011), Amorim (2011), Alvez e Evanson (2013), e Glenny (2016). De forma complementar às fontes bibliográficas consultamos artigos de jornais e a forma complementar as fontes bibliograficas consultamos artigos de jornais e a
rede mundial de computadores (nesse caso a plataforma da rede social do Facebook nos foi muito útil).
Janeiro tem sido transfigurada num espaço de batalha tridimensional e como políticas urbicidas, de "destruição" e negação deliberada da cidade, têm sido introduzidas por esse viés no cotidiano urbano. Para isso empregaremos os conceitos propostos no artigo com o intuito de contribuir com uma análise crítica das relações de controle territorial das periferias urbanas e das relações do Estado e suas instituições com as classes periféricas. Para atender o objetivo, o estudo foca na ação do tráfico de drogas e da polícia, os principais atores históricos da militarização da cidade, em detrimento de outros, como as milícias, de atuação mais recente.

\section{Volumetria política do tráfico de drogas e da polícia}

A militarização do espaço urbano carioca pressupõe intrinsecamente, a criação de dispositivos de segurança que visam disciplinar e controlar as pessoas. A polícia, por excelência, seria o dispositivo de segurança criado pelo Estado moderno, como Foucault (2008) observa. Em resumo, o que Foucault já havia antevisto, o processo de distribuição de dispositivos de controle na sociedade promoveu a passagem de um Estado regulado pelo "poder soberano" (fundado no controle estratégico do território e seus recursos) e da "sociedade disciplinar" (pautada em organizar grandes meios de confinamento) para uma "sociedade de controle social" (centrada no aperfeiçoamento das táticas de controle da população). Sob esse último estágio surgiria a noção de governamentalidade (que propõe a gestão governamental), então articulada com as formas mais antigas de poder (soberania e disciplina) incorporadas a uma só estrutura, já que as precedentes não desaparecem, mas se dão como forças implicadas, ou, mesmo, amalgamadas a partir de então (ver FOUCAULT, 2008, 2013).

Nessa lógica, de permanência e até mesmo de multiplicação de dispositivos de segurança ${ }^{7}$ na sociedade, cabe-nos analisar o processo de militarização do terreno urbano e o de configuração de uma matriz urbano-volumétrica que se presta a assegurar o controle do volume ${ }^{8}$, ou seja, o controle do ambiente urbano como conteúdo tridimensional de um dado substrato espacial e do seu habitar, que caracterizam a vida na cidade a partir da perspectiva da introdução de dispositivos de segurança "espaciais" que marcam o retorno da cidade ao palco central das lutas ao se conceber o teatro urbano

${ }^{7}$ Dispositivos de segurança são, em outras palavras, dispositivos de controle, por isso, algumas vezes optamos pelo uso da palavra controle, quando entendemos que ela melhor atende aos anseios do texto.

${ }^{8}$ Assegurar o controle do volume político para assim exercer o controle em profundidade se torna essencial, nos dias de hoje, para um efetivo controle do território, como observam Elden (2013) e Weizman (2002, 2004, 2012) 
como um espaço de batalha. Por efeito dessa lógica, no contexto da realidade urbana brasileira, em especial do Rio de Janeiro, emergem dinâmicas específicas de desterritorialização, que em parte se justapõem umas às outras e se atritam entre si, em virtude de tensões e alterações em matéria de relações de poder e do emprego de estratégias para se exercer o controle.

Dados os processos dinâmicos que se dão pela disputa de territórios entre facções do tráfico e o Estado, é preciso salientar que os dispositivos de controle de outrora, executados durante os anos 1980-1990, não são exatamente os mesmos. 0 surgimento de dispositivos de controle volumétrico, aparelhado em um espaço físico e na apropriação da infraestrutura e na oferta de serviços urbanos, caracteriza-se hoje não somente pela militarização de atores não estatais (distribuídos geograficamente sobreas áreas segregadas), que passam a exercer o monopólio da violência. Hoje, as favelas estão imersas em diferentes modalidades de controle territorial, conduzidos pelo Estado ou por grupos milicianos, que atritam com o tráfico e que operaram pela acomodação e a sobreposição de diferentes territorialidades do tráfico, em vez de pura e simplesmente substituí-las. Ambas as formas territoriais de controle agem no sentido de se apropriar da infraestrutura física e da oferta de serviços urbanos para extrair dividendos que estão relacionados à precarização das condições de existência urbana dos mais pobres ${ }^{9}$.

$\mathrm{Na}$ análise dessa questão é importante salientar, inicialmente, que os traficantes não querem destruir o sistema, pois eles próprios são, na verdade, produtos dele, funcionando como acomodações no interior do sistema, como lembra Souza (2008). Possuem uma

[...] relação objetiva e subjetivamente ambígua com o Estado (e com os capitalistas): são reprimidos por ele em sua face "oficial" e, ao mesmo tempo, mantidos por agentes estatais corruptos (policiais e outros). No tabuleiro de xadrez do comércio de drogas ilícitas, os "donos" são "pequenos capitalistas informais/ criminosos", cuja existência é impensável sem o "subsistema I-E-A" [Importação-Exportação-Atacado], perante o qual eles são pouco mais que simples peões e os seus "soldados" e "gerentes" (mão-de-obra barata, que pode ser reposta a custo quase zero) menos até que isso, para não falar nos ainda mais descartáveis "olheiros", "aviões" e "vapores". Esse "hiperprecariado armado" não constitui, a rigor, um "exército industrial de reserva". A distância entre esses jovens (não raro crianças) semi-alfabetizados, em geral pouco ou nada qualificados mesmo para trabalhos manuais, filhos e netos de trabalhadores muitas vezes informais, e as exigências do setor formal (não só na indústria, mas também no terciário) é muito grande (SOUZA, 2008, p. 133-134).

${ }^{9}$ Dinâmicas de exclusão socioespacial estão ligadas à crescente dinâmica de territorialização precária, denominadas por Haesbaert $(2007,2009)$ de aglomerados humanos de exclusão.
Os traficantes se beneficiam do processo de precarização das condições de trabalho e vida na cidade, territorializando sua força em espaços frágeis sobre os quais podem impor suas leis e estender seus tentáculos à população pelo emprego de mecanismos assistencialistas. Ao operar por lógicas territoriais multiescalares, o tráfico faz uso de espaços zonais e descontínuos, seja a partir dos enclaves territoriais que as favelas ajudam a configurar, seja pelo aproveitamento de ruas e vielas estreitas, que, dificultam o acesso e a ação da polícia, ou pela utilização de redes materiais (estradas, por exemplo, que garantem acesso ao mercado consumidor, portos ou pistas de voo por onde a droga entra) e virtuais (celulares, de onde, por exemplo, os chefes das facções criminosas controlam o tráfico de dentro dos presídios), que conectam os espaços, dandoIhes um sentido funcional. Por essas sobreposições e articulações, a depender da escala, os traficantes de varejo configuram um poder local e um território-rede que movimenta diferentes fluxos (ver SOUZA, 2005, 2008; e MACHADO, 2005).

Pelo subsistema I-E-A - "importação-exportaçãoatacado" - do comércio de drogas ilícitas configura-se a escala de ação do tráfico de drogas, de grupos que vão atuar a partir do "subsistema varejo", quando as quadrilhas operam com o apoio logístico de favelas e outros espaços segregados, controlando os fluxos de abastecimento e distribuição do produto. 0 caráter territorial desse domínio nas favelas e em espaços segregados se manifesta pela subordinação, direta ou indireta, das organizações cívicas e da população como um todo aos traficantes.

Na matriz territorial produzida pelo tráfico no controle de uma favela, a quadrilha apropria-se de uma complexa rede de becos, vielas e escadarias, interligadas, que conforma, nesse aspecto, uma cartografia de volumes empregada a favor do tráfico. A tipologia labiríntica e a topografia acentuada de muitas favelas do Rio de Janeiro são aproveitadas para impedir ou dificultar a penetração de policiais ou grupos rivais que se infiltram na favela. Como território estratégico para as ações do tráfico, os morros cariocas são mais do que o resultado residual do processo de segregação espacial. Os morros consistem num espaço que foi militarizado pela presença dos traficantes e, posteriormente, pela polícia, com a instalação das UPPs. São espaços segregados que oferecem condições físicas e sociais - isto é, um meio social, mas também topográfico - para a ação do tráfico. 0 aspecto "novo" da geopolítica da favela é que as formas de controle territorial do tráfico e da polícia hoje convivem juntas num mesmo território, por sobreposições de ordem de escala e rearranjos, 
ocasionando um controle territorial mais flexível.

A dimensão territorial do tráfico de drogas, dos anos 1980-90, que conformava assim uma espécie de "arranjo espacial", formado por anéis cilíndricos, justapostos e expressos pela "divisão do trabalho" entre membros da quadrilha, que refletem a ordem espacial volumétrica de controle (constituída espacialmente ao longo do gradiente topográfico pela composição de uma estrutura funcional do tráfico de varejo, pelos "olheiros", "soldados", "gerentes", "dono do morro" etc., cada qual desempenhando um papel mais específico no nível volumétrico) associada à geografia de uma dada favela, não faz mais sentido em muitas favelas "pacificadas", onde se instalou a Unidade da Polícia Pacificadora (UPP). 0 modelo territorial do tráfico de drogas, que consiste no controle de uma área vital, de feição espacial areolar, amparado no controle das áreas, tem-se esmiuçado numa fragmentada e flexível ordem territorial volumétrica de territórios sobrepostos e complexos, em que a lógica zonal (controle da área) ou reticular (controle da rede) não dá conta de sua compreensão ${ }^{10}$. Suas fronteiras, marcadas por lugares mais ou menos estáticos, definidos por um equilíbrio através de fronteiras lineares e fixas, têm-se tornado mais instáveis e elásticas. Verdadeiras linhas temporárias móveis, que tanto podem ser ativadas como desativadas, se expandem e se encolhem de acordo com a sinergia do modelo e das forças em interação.

Além da funcionalidade espacial, é importante levar em conta que o território do tráfico pode se desfazer momentaneamente sem que isso implique perda de referenciais socioculturais e dos vínculos territoriais com o espaço. Trata-se, com efeito, de uma qualidade que denota uma estratégia de comportamento temporal e adota ao extremo uma concepção de "território flutuante", de aspecto flexível e de essência sazonal, que pode aparecer e desaparecer ou mesmo se reinventar, a depender das circunstâncias e das dinâmicas em interação no espaço. Dessa forma, uma quadrilha que exerce o controle sobre uma favela pode, por pressão da polícia ou por investida de algum grupo rival, vir a recuar, ainda que forçosamente, a fim de reorganizar suas forças para defender o território. Contudo, isso não significa, em suma, que eles tenham sido desterritorializados em absoluto. Na verdade, essa manobra pode significar uma estratégia ou até mesmo um comportamento correspondente aos modos operantes da territorialidade do tráfico de agir de maneira mais flexível, apresentando, assim, maior mobilidade territorial.

Uma quadrilha diante de um ataque de um grupo invasor, prevendo muitas baixas ou uma derrota eminente,

${ }^{10}$ Para mais detalhes sobre as concepções de território-zonal e de território-rede, ver Souza (2009) e Haesbaert (2007). pode recuar para um determinado setor da favela que topograficamente lhe favorece, para que consiga reunir forças na tentativa de tirar vantagem do terreno, isto é, de um volume político, ainda que isso signifique ceder momentaneamente parte de seu território ao inimigo. Faz parte dessa estratégia deslocar as "bocas de fumo" para outras áreas, evitando que a droga seja capturada pelo inimigo ao mesmo tempo em que mantém para a facção, apesar da situação de litígio, a rotatividade de lucro pela venda da droga. Deve-se considerar também que moradores que dão suporte ou são associados à quadrilha local ainda permanecem, caso não sejam expulsos, como os olhos da quadrilha local, podendo, inclusive, fornecer informações de dentro da favela ou até mesmo ajudar na retomada do território.

Diante de uma invasão policial a quadrilha local pode simplesmente fugir ou se esconder dentro da favela até que a retirada dos policiais possibilite 0 retorno às atividades e o restabelecimento do território de forma quase que imediata. Em todo caso, a rede de comunicação a serviço do tráfico não é menos imprescindível quando os inimigos são as forças policiais: para o exercício do poder, possuir uma boa rede de informação sempre foi, como destaca Raffestin (1993), fundamental para o controle do território. Nas áreas controladas pelo tráfico, essa afirmação é aplicada à risca, pois, além do suborno pago aos policiais e da colaboração de alguns moradores, os traficantes usam radiotransmissores e outros recursos para se comunicar de forma sincronizada com os comparsas em situações de emergência, assegurando assim o controle do volume político.

Com a instalação das UPPs ${ }^{11}$ e a chegada das milícias o tráfico tem sido forçado a dividir o controle dos territórios sobre os quais antes reinava absoluto.

Em algumas áreas é possível notar uma aparente divisão do território da favela entre o tráfico e a polícia. $\mathrm{Na}$ Rocinha, em particular, cabe à polícia o controle da via principal - a estrada da Gávea - e as duas entradas, uma na parte baixa na grande área comercial da Rocinha, que conecta a favela ao bairro de São Conrado, e a outra no alto, pelo Laboriaux. A Rua 1 bem como becos e vielas, suas adjacências e as franjas urbanas que delimitam o território da Rocinha permanecem no controle do tráfico, sendo para a polícia quase um suicídio se afastar do traçado principal (estrada da Gávea) e entrar em becos no interior da favela. A favela foi nitidamente subdivida em territórios fragmentados que coexistem em função

\footnotetext{
${ }^{11} \mathrm{O}$ programa de segurança pública que deu origem às UPPs começou a funcionar em 19 de dezembro de 2008, quando foi instalada a primeira Unidade de Polícia Pacificadora, no morro Santa Marta, no bairro de Botafogo, na Zona Sul. Desde então, segundo informações de um site do governo (<http://www.upprj.com/>), 38 UPPs foram implantadas. Atualmente, segundo essa mesma fonte, a Polícia Pacificadora conta com um efetivo de 9.543 policiais. (Consulta ao site se deu em 29 de julho de 2017).
} 
de estarem em níveis topográficos e volumétricos distintos. O narcotráfico assegura, por exemplo, o controle da Rua 1, o mais importante bastião do tráfico local, mantendo, com apoio dos olheiros, uma complexa logística de controle de vielas e becos, para, assim, assegurar o controle do volume político vital ao tráfico de drogas. Deve-se levar em consideração ainda que numa favela de grande extensão territorial como o da Rocinha pode haver mais de uma facção operante, cada uma apoiando-se em suporte volumétrico distinto para garantir o acesso a certos recursos. A territorialidade do tráfico pode alterar-se, mas seu "centro nervoso" irriga inúmeras vielas e becos, assegurando, pela lógica volumétrica, o controle territorial de fluxos constantes em detrimento da presença da polícia, que se fixa em outro estrato espacial.

Enquanto os policiais são vistos circulando pelas principais vias da favela, o tráfico permanece operante nas franjas territoriais ou na profundidade territorial constituída, em aspecto físico, por vielas e becos estreitos, que conformam, pelo controle volumétrico flexível, um importante dispositivo de defesa. 0 carioca chama de "gato" e "rato" a ação do tráfico em relação à da polícia na favela da Rocinha e no morro Santa Marta. A polícia, em sua ação de perseguição, é denominada gato, enquanto o traficante em constante fuga seria o rato. Isso reflete a aparente ideia de que o tráfico não exerce controle territorial, o que não é verdade. 0 tráfico continua atuando com o suporte da favela, mas a partir de uma lógica territorial flexível, que requer, em vez do controle zonal e/ou reticular fixo e estático dos limites e de suas redes, isto é, de postos-chave, o controle de volumes flexíveis. Pode exercer, em determinados pontos da favela, certo controle territorial efetivo, mas sua territorialidade se expressa, de fato, pelo aspecto flexível e elástico, mudando de lugar a depender das circunstâncias. Tal controle é efetivo por se apoiar em dispositivos de segurança ópticos que contam com o apoio de (alguns) moradores.

Por outro lado, embora o modelo de pacificação das UPPs esteja em deterioração, o modo operante de ocupação ostensiva tem adquirido um aspecto mais volumétrico de repressão e de supressão do espaço público e privado, que não se limita ao combate do tráfico, mas estende suas ações de controle sobre os moradores e aos espaços internos de suas casas e vida em família. No complexo do Alemão, em Nova Brasília, Zona Norte do Rio, por exemplo, um antigo reduto do Comando Vermelho e uma das áreas mais conflagradas da cidade, os policiais foram acusados de ocupar residências de moradores para utilizá-las como proteção e posições de tiro. Numa "guerra" por posições, por volumes, em outras palavras, as casas estavam sendo usadas como trincheiras urbanas. Como parte da estratégia de avanço no território inimigo, os policiais ficavam por vários dias dentro das casas dos moradores, sem autorização dos donos.

Em reportagem para o $\mathrm{G} 1$ Globo, de 5 de maio de 2017, o repórter Marco Martins detalha que a Defensoria Pública e integrantes da Comissão de Direitos Humanos, ao irem ao local, constataram que a polícia estava usando as casas como base militar. Lá encontraram ventiladores e colchonetes, além de restos de comida abandonados apressadamente pela polícia, quando esta soube da presença dos defensores públicos. Os policiais permaneciam na frente das casas invadidas e sobre as lajes de alguns imóveis. Haviam feito perfurações em algumas casas para alojar as metralhadoras e disparar as armas de dentro das casas.

Segundo essas mesmas denúncias feitas à Defensoria Pública (entre abril e maio de 2017), os policiais não se limitavam a ocupar o recinto, mas, em flagrante violação, também devoravam tudo o que havia na geladeira das casas invadidas. Um morador disse, ainda, em denúncia no dia 3 de maio, ter sido expulso, juntamente com a família, de sua casa pela polícia, que passou a ocupála. Em outro depoimento perturbador, "uma senhora, moradora de uma casa com dois pavimentos, passou a colocar móveis e objetos atrás da porta na tentativa de evitar que os policiais permanecessem invadindo a sua residência. Eles arrombaram a fechadura da porta inúmeras vezes", contou a defensora Lívia Cásseres (ver MARTINS, para G1 Globo, 5 de maio de 2017).

Nessa mesma área, em abril de 2017, a polícia já havia terminado de construir uma torre blindada (ver Figura 1) no Largo do Samba, em Nova Brasília, que trouxe a intensificação dos confrontos na região durante $\mathrm{o}$ andamento das obras no local. A torre de dois pavimentos posicionada num ponto de venda de drogas de difícil acesso para a polícia até então consiste numa estrutura que se assemelha a uma torre medieval, só que de aço, situada no meio da rua (ver GOULART, FOLETTO, COSTA; para $O$ Globo Rio, 25 de abril de 2017). Trata-se de um dispositivo com fins militares que monitora os transeuntes. Assim como as UPPs, a torre blindada, sem ressalvas, faz parte de um dispositivo militar avançado, introduzido no território, que ajuda a configurar o terreno urbano como um espaço de batalha volumétrico.

Sem rastro social de reconhecimento dos moradores como medidas legítimas, esses dispositivos, na prática, têm servido para acentuar os conflitos e gerar um ambiente altamente militarizado, que consiste na configuração das favelas e espaços segregados como áreas conflagradas. 0 Estado estaria agindo, nesse 
sentido (tal como os traficantes ou milicianos), como produtor e gestor do espaço de batalha, criando um arranjo espacial militarizado, ao inserir a vida urbana em permanente estado de conflito manifesta em políticas públicas de segurança que metaforizam o discurso da guerra e introduzem estruturas militares no terreno urbano. Uma vez acoplados ao tecido urbano, esses dispositivos passam a fazer parte da arquitetura urbana

Figura 1: Mostra a finalização da torre blindada, no Largo do Samba, em Nova Brasília, RJ, instalada pela polícia. Sua fisionomia lembra uma torre medieval ou mesmo os pontos de checagem introduzidos por Israel na Palestina para controlar os fluxos interfronteiriços nos territórios ocupados.

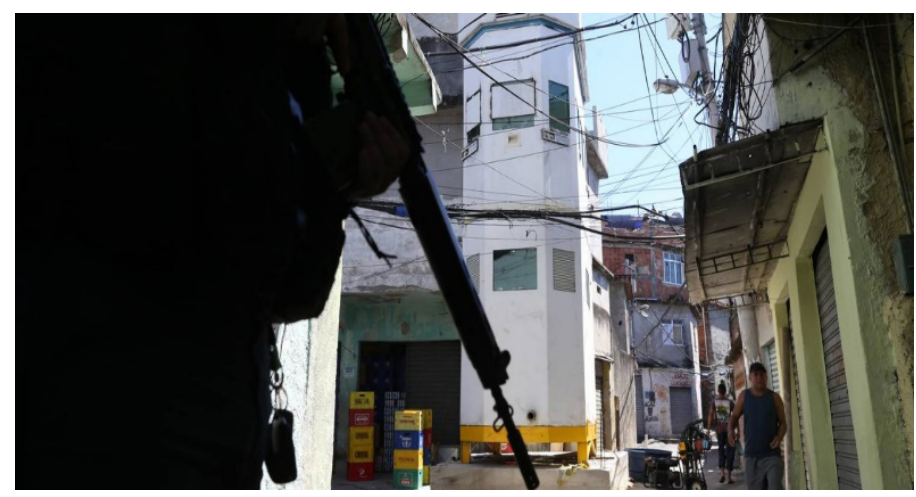

Fonte: Márcia Foletto para o Globo Rio, 25 de abril de 2017.

de controle e enfrentamento ao tráfico de drogas que extrapolam o viés de respeito à vida e à dignidade, transformando o espaço urbano, como um todo, numa infraestrutura de repressão à população que mora nessas áreas, como inúmeros depoimentos dão conta. Tais ações são justificadas pelo discurso midiático que exaltam a intervenção militar como a única alternativa de combate ao crime.

Pela introdução desses dispositivos teríamos a configuração de uma matriz de poder volumétrico que se funda no controle de volumes, em vez do controle de superfícies. Essa matriz territorial, que configura um espaço tridimensional como um "território volumétrico" a expressão não seria exagero -, se acomoda e interage em perspectivas visuais, conforme as quais é preciso assegurar o controle do volume tanto das residências dos moradores (controle interno) quanto da vigilância dos transeuntes na rua (controle externo). Esse volume político daria origem, então, a um sistema de objetos ópticos militarizados, acoplados à cidade, que são responsáveis pelo aumento da violência urbana e pela configuração do terreno urbano em espaço de batalha complexo, responsável por causar o encolhimento do espaço urbano, seja público ou privado, quando não mais ocorre distinção entre moradores e transeuntes da lógica de guerra.

A partir desta modalidade de controle territorial, o toque de recolher, usado pelos traficantes para fechar o comércio, como uma forma de retaliação e imposição de sua força, vem cada vez mais sendo empregado também pelas forças policiais. Tal estratégia de manipulação e de controle do terreno urbano a partir da proibição de circular em certos horários, em vez de alterar a morfologia do terreno, concorre para restringir a mobilidade das pessoas, "esvaziando" o território onde vigora essa medida de exceção. Nesse sentido:

\begin{abstract}
0 toque de recolher pode ser visto como técnica de exercício de poder em termos de uma contenção territorial "invisível", cuja expressão espacial pode não ter referenciais materiais claros, mas onde quem vive nessas áreas reconhece exatamente até onde se estende a "lei" do narcotráfico - até porque muitos traficantes delimitam claramente a área de sua "ronda" para constranger moradores. Trata-se, podemos dizer, de uma contenção temporária, focada mais no controle do tempo (o horário em que a mobilidade é restringida) do que do espaço (embora, obviamente, este também seja delimitado). (HAESBAERT, 2014, p. 259-260)
\end{abstract}

No caso do emprego do toque de recolher em operações militares ou em territórios "pacificados", o foco está na estratégia de supressão do espaço público, como via de circulação, trocas e relações sociais e lugar de lazer do favelado. Assim, o espaço mais importante do favelado, que, além de seu lugar de moradia, deveria ser reservado para usufruto de uma espécie de "modo" de vida urbano, permitindo a esse morador participar de festas ao ar livre e de bailes funk, por exemplo, tende a ser debilitado por tais medidas de exceção. 
A polícia pode, dessa maneira, suprimir o espaço de convivência social, proibindo festas e atividades culturais ao ar livre ou até mesmo intimidar moradores. Na favela da Rocinha, por exemplo, soldados das Forças Armadas foram vistos com máscaras de caveira cujo uso não é restrito ao combate a grupos de traficantes, mas serve para esconder a identidade do soldado. Assim, este poderá até cometer assassinatos, atuando fora da lei, sem ser identificado. Soldados mascarados e armados circulando pelas vias e becos da favela transmitem a mensagem simbólica de que são uma força de extermínio e que estão ali para matar, esvaziando o espaço público de convivência dos moradores, que ficam naturalmente com medo ${ }^{12}$. Essa estratégia é empregada para anular o volume político do tráfico, já que, não havendo moradores nas ruas e praças, fica fácil para a polícia identificar os traficantes e patrulhar as ruas. Sem pessoas na rua o território volumétrico do tráfico se torna um terreno urbano estéril para suas atividades.

Outra estratégia da polícia consiste em erguer muros dentro da favela em becos e vielas estreitas com o intuito de dificultar a fuga de traficantes. Essa estratégia de contenção já é usada pelo tráfico há algum tempo. É curioso que tem sido replicada agora pelos policiais.
No caso do tráfico de drogas, os traficantes podem colocar nas principais vias de acesso blocos de cimento e pedras, ou até vigas e trilhos de aço, instaladas nas ruas, constituindo uma espécie de guarita para impedir a entrada de viaturas da polícia. Esses bloqueios são resistentes o suficiente para impedir a entrada dos blindados da polícia, chamados Caveirões. Seu emprego também serve para filtrar a entrada das pessoas que circulam pela favela. Consiste, em certo modo, numa adaptação do checkpoint israelense, que controla os fluxos de palestinos. Os traficantes podem também construir muros ou colocar portas de aço em becos que dão acesso a outras favelas, impedindo a entrada de inimigos procedentes de outros territórios. Trata-se, portanto, de uma estratégia de contenção territorial, que podemos chamar de "bloqueio defensivo" do tráfico de drogas. Serve para inviabilizar a infiltração de inimigos e assegurar um melhor controle de volumes essenciais à ação da quadrilha.

Já a polícia usa essa estratégia como uma forma de alterar a malha urbana da favela para impedir a fuga de criminosos e o efetivo exercício do controle territorial pelo tráfico, que se apoia na tipologia labiríntica da favela. 0 emprego deste tipo de estratégia urbana de

Figura 2: Em um post na rede social do Facebook, Raull Santiago, morador do Complexo do Alemão e membro do Coletivo Papo Reto, denunciou, através da rede de computadores, a construção de um muro na favela por policiais. Notícias de que policiais estão fazendo bloqueios em becos e vielas na favela, usando para isso blocos de cimento e sacos de areia, circulam pela internet.

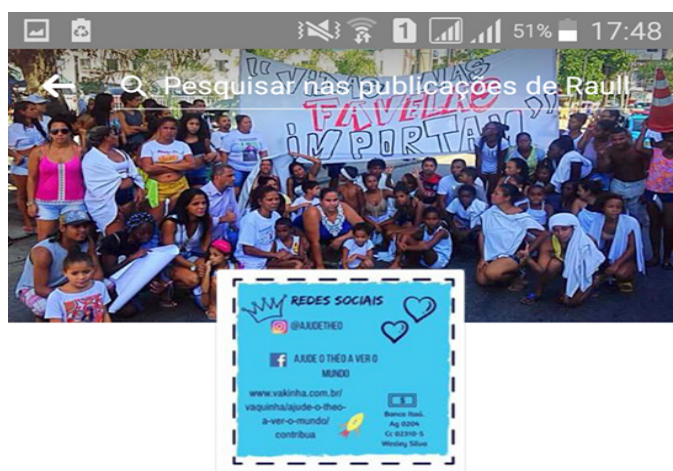

Raull Santiago (Coletivo Papo Reto)

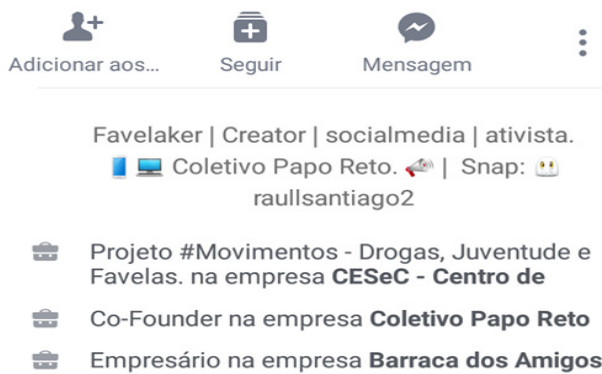

${ }^{12}$ Sobre soldados mascarados na favela da Rocinha pode-se consultar a reportagem intitulada Máscaras de caveira são a cara do desrespeito aos direitos constitucionais na Rocinha, publicada em 27 de setembro de 2017 pela redação do Esquerda Diário e disponível no mesmo site: (<http://www.esquerdadiario.com.br>)

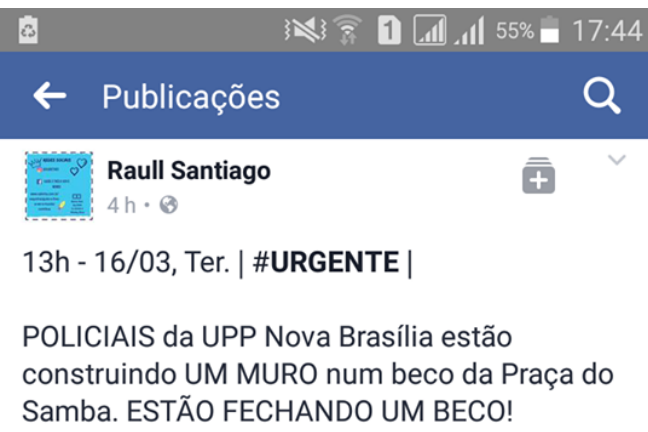

Estão cerceando o direito de ir e vir de alguns moradores e moradoras, de forma gravíssima.

Já não bastante as casas invadidas e as tantas mortes por conta daquela "Cabine da Vergonha", agora isso! INACEITÁVEL.

É loucura, ego e muito esculacho a forma como atuam policiais dessa UPP, atropelando direitos, desrespeitando as leis, usando de terror e violência no seu modos operandi!

MORADORA: "Quando eu passei para ir na minha mãe, eles estavam lá fazendo o muro..." 
$O$ comando local DEVE ser cobrado e retirado do COMPLEXO DO ALEMÃO, isso é URGENTE, pois a gravidade e variedade de violações de direitos que são cometidas nessa área são uma barbarie.

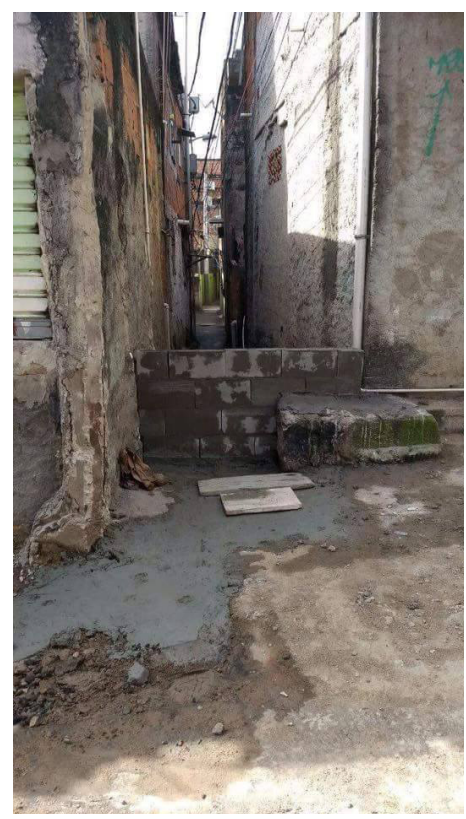

Fonte: perfil de Raull Santigo, do Coletivo Papo Reto, no Facebook, 16 de março de 2017.

combate ao tráfico que envolve construção tem por sua finalidade "anular" a morfologia labiríntica da favela, que os traficantes usam ao seu favor para fugir e se defender da polícia. Essa estratégia de desarticular os volumes do tráfico modificando os circuitos internos de interação na favela pode, nesse sentido, ser denominada, queremos propor, "contenção labiríntica", já que seu foco de ação é evitar a evasão dos traficantes, criando uma espécie de cerco urbano, impedindo a sua fuga (ver Figura 2). Faz-se necessário mencionar que, embora essas vias possam ser usadas pelo tráfico, também consistem em vias de uso de moradores. Seu bloqueio é uma violação do direito mais básico.

Tais estratégias demonstram explicitamente, no cotidiano urbano dos moradores, uma tendência de intervenção que manipula o espaço urbano, tanto por parte do tráfico quanto das forças policiais. No caso da ação da polícia, embora a remoção de obstáculos da via pública para efetuar a detenção de traficantes e liberar o trânsito não incorra na destruição do espaço urbano há a construção e alteração do arranjo espacial, que se dá mediante instalação de bases da polícia ou construção de muros e estabelecimento de bloqueios. Ressaltase que estas duas últimas estratégias são efetuadas também pelo tráfico. No fundo, a política volumétrica tem produzido um ordenamento de controle e apropriação da infraestrutura urbana, que se manifesta aqui não só nas incursões militares de fora do território, mas através da ocupação e presença permanente de forças policiais e do tráfico no terreno urbano, pelo controle do volume político. Nesse aspecto, a instalação das Unidades da Polícia Pacificadora e a presença do tráfico no território criam um dispositivo de controle que interage com os moradores, que pode assumir a função repressiva partindo de dentro do território.

O controle da infraestrutura física e da oferta urbana de serviços que tais grupos assumem pode configurar uma ação urbicida, que consiste na precarização das condições urbanas de vida na cidade, inviabilizando, através do uso da violência política, o acesso da população a certos recursos. Nesse mesmo sentido, a ação do tráfico ou a da polícia podem ainda expulsar moradores de suas residências, revelando, assim, a essência da atividade urbicida, que consiste em negar de forma deliberada a um determinado indivíduo ou grupo o acesso às condições urbanas de vida na cidade. O modo operante do urbicídio assume, dessa forma, o viés da violência política, no qual há a manipulação do terreno urbano para reprimir ou expulsar contingentes populacionais, impedindo o uso do espaço urbano como lugar de variadas interações sociais. Esse tipo de violência empregada para suprimir o espaço público ou expulsar moradores gera um processo de "homogeneização" do espaço urbano do favelado, que não pode mais se expressar ou fazer reinvindicações através do substrato urbano de sua existência mais imediata na cidade. 
Ourbicídio pode ainda evoluir para políticas destrutivas do arranjo espacial urbano de maior letalidade, como tudo indica. Sua evolução está diretamente relacionada com o aprofundamento do estado de exceção, que incorre na produção de cidades sitiadas. A "crise" econômica e o "caos" urbano induzidos como situação política manipulada pode ser o estopim e o salvo-conduto para a violência urbicida extrema. Com efeito, o emprego de estratégias de controle essencialmente volumétricas tem induzido a supressão do espaço público e transformado favelas e periferias urbanas num "virtual" espaço de batalha, enquanto a cidade legal, propriamente dita, permanece em "paz". No caso do Rio, pela lógica atual, em que o mote da política de segurança pública tem se dado pela estratégia de ocupar os territórios em domínio do tráfico para expulsar e desarmar traficantes, é perfeitamente plausível imaginar, diante de tais fatos, que estaria em curso no Rio de Janeiro, pelo modelo de militarização adotado, a configuração de uma "cidade carcerária".

A cidade cárcere que está insurgindo no Rio de Janeiro apresenta zonas de contenção já bem definidas que se justapõem, na perspectiva aqui apresentada, à configuração de espaços de batalha, situados nas favelas e áreas segregadas, a partir da gerência de um Estado ainda mais autoritário em gestação. Na medida em que o Estado não consegue "pacificar" os territórios em domínio do tráfico, acaba por privilegiar, tão somente, uma política de contenção e encarceramento de seus moradores, que são trancafiados nos enclaves territoriais onde a violência é maior.

Observa-se que a militarização da cidade tem configurado o terreno urbano em espaço de batalha complexo. Tal complexidade, antes de ser expressar pela militarização, exprime-se pela "des-ordem" espacial e tipologia labiríntica que caracterizam muitas favelas do Rio de Janeiro, revelando, portanto, o discurso enviesado do militarismo em conceber o substrato urbano da periferia como perigoso. Uma vez definida a favela como espaço "caótico" e lugar de "bandido", a partir do uso substancial do estereótipo, de fundo racista, do pobre e do negro em conotação negativa, o substrato urbano e seus moradores podem ser concebidos como inimigos, justificando, nessa medida, estratégias urbicidas que levam à supressão do espaço público e a remoções forçadas. Seu modo operante, pela forma que vem adquirindo, tem transfigurado a vida urbana em lógicas urbicidas volumétricas, focalizadas contra grupos vulneráveis, já que expressa uma concepção tridimensional de controle do terreno urbano manipulado para negar o urbano e destruir as condições de permanência na cidade. 


\section{Referências}

ALVES, Maria H. Moreira; EVANSON, Philip (2013). Vivendo no fogo cruzado: moradores de favela, traficantes de droga e violência policial no Rio de Janeiro. São Paulo: Editora Unesp.

AMORIM, Carlos (2011). Comando Vermelho. Rio de Janeiro: BestBolso.

BARCELLOS, Caco (2003). Abusado: o dono do Morro Dona Marta. Rio de Janeiro: Record.

BATISTA, Vera Malaguti (2003). O medo na cidade do Rio de Janeiro: dois tempos de uma história. 2. ed. Rio de Janeiro: Revan.

COWARD, Martin (2009). Urbicide: the politics of urban destruction. Nova York: Routledge.

ELDEN, Stuart (2013). Secure the volume: vertical geopolitics and the depth of power. Political Geography, v. 34, p. 35-51, maio.

FOUCAULT, Michel (2008). Segurança, território, população: curso dado no Collège de France (1977-1978). São Paulo: Martins Fontes.

(2013). Vigiar e punir: nascimento da prisão. 41. ed. Petrópolis: Vozes.

GLENNY, Misha (2016). O dono do morro: um homem e a batalha pelo Rio. São Paulo: Companhia das Letras.

GOULART, Gustavo; FOLETTO, Márcia; COSTA, Célia (2017). Após cinco dias de tiroteios e quatro mortes, torre blindada é instalada no Alemão. O Globo Rio. Rio de Janeiro, Brasil, 25 de abr. 2017. Disponível em: <https://oglobo.globo.com/ rio/>. Acessado em: 29 de jul. de 2017.

GRAHAM, Stephen (2011). Cities under siege: the new military urbanism. Londres: Verso.

; HEWITT, Lucy (2012). Getting off the ground: on the politics of urban verticality. Progress in Human Geography, v. 37, p. $72-92$.

HAESBAERT, Rogério (2009). Desterritorialização: entre as redes e os aglomerados de exclusão. In: CORRÊA, Roberto Lobato; GOMES, Paulo C. da Costa; CASTRO, Iná Elias de (orgs.). Geografia: conceitos e temas. 12. ed. Rio de Janeiro: Bertrand Brasil, p. 165-205.

(2007). O mito da desterritorialização: do "fım dos territórios" à multiterritorialidade. 3. ed. Rio de Janeiro: Bertrand Brasil.

(2014). Viver no limite: território e multi/transterritorialidade em tempos de insegurança e contenção. Rio de Janeiro: Bertrand Brasil.

MACHADO, Lia Osório (2005). O comércio ilícito de drogas e a geografia da integração financeira: uma simbiose? In: CORRÊA, Roberto Lobato; GOMES, Paulo C. da Costa; CASTRO, Iná Elias de (orgs.). Brasil: questões atuais da reorganização do território. 3. ed. Rio de Janeiro: Bertrand Brasil, p. 15-64.

MARTINS, Marco Antônio (2017). Moradores do Alemão dizem que policiais continuam ocupando residências, mas $P M$ nega invasões. G1 Globo. Rio de Janeiro, Brasil, 5 de maio 2017. Disponível em: <http://g1.globo.com/>. Acessado em: 29 de jul. de 2017.

Máscaras de caveira são a cara do desrespeito aos direitos constitucionais na Rocinha. Esquerda Diário. Brasil, 27 de set. 2017. Disponível em: <http://www.esquerdadiario.com.br>. Acessado em: 25 de fev. 2018.

MISSE, Michel (2011). Crime e violência no Brasil contemporâneo: estudos de sociologia do crime e da violência urbana. Rio de Janeiro: Editora Lumen Juris.

RAFFESTIN, Claude (1993). Por uma geografia do poder. São Paulo: Editora Ática S.A.

SHARP, Deen. (2016). Urbicide and the arrangement of violence in Syria. In: SHARP, Deen; PANETTA, Claire (orgs.). Beyond the square: urbanism and the Arab Uprisings. New York: Urban Research, p. 118-140.

SOARES, Luiz Eduardo (2000). Meu casaco de General: 500 dias no front da segurança pública no Rio de Janeiro. São Paulo: Companhia das Letras. 
SOUZA, Marcelo Lopes de (2005). As drogas e a "questão urbana" no Brasil. A dinâmica socioespacial nas cidades brasileiras sob a influência do tráfico de tóxicos. In: CORRÊA, Roberto Lobato; GOMES, Paulo C. da Costa; CASTRO, Iná Elias de (orgs.). Brasil: questões atuais da reorganização do território. 3. ed. Rio de Janeiro: Bertrand Brasil, p. 419468.

(2008). Fobópole: o medo generalizado e a militarização da questão urbana. Rio de Janeiro: Bertrand Brasil.

(2009). O território: sobre espaço e poder, autonomia e desenvolvimento. In: CORRÊA, Roberto Lobato; GOMES, Paulo C. da Costa; CASTRO, Iná Elias de (orgs.). Geografia: conceitos e temas. 12. ed. Rio de Janeiro: Bertrand Brasil, p. 77-116.

WEIZMAN, Eyal (2012). Hollow land: Israel's architecture of occupation. Nova York: Verso.

(2004). Strategic points, flexible lines, tense surfaces, and political volumes: Ariel Sharon and the geometry of occupation. In: GRAHAM, Stephen (org.). Cities, war and terrorism: towards an urban geopolitics. Oxford: Blackwell Publishing Ldt, p. 172-191.

(2002). The politics of verticality. Open Democracy. Londres, Inglaterra, texto de 11 partes disponibilizado entre 23 de abril e 1 de maio de 2002. Disponível em: <http://www.opendemocracy.net/>. Acessado em: 26 de mar. 2014. 